Technical Note

\title{
Design and Performance Evaluation of a Multi-Tuber Peeling Machine
}

\author{
Adeshina Fadeyibi ${ }^{1, *(1)}$ and Olusola Faith Ajao ${ }^{2}$ \\ 1 Department of Food and Agricultural Engineering, Kwara State University, Malete, \\ Ilorin P.M.B. 1530, Kwara State, Nigeria \\ 2 Department of Agricultural and Biosystems Engineering, Landmark University, \\ Omuaran P.M.B. 1001, Kwara State, Nigeria; ajao.faith@lmu.edu.ng \\ * Correspondence: adeshina.fadeyibi@kwasu.edu.ng; Tel.: +234-(0)-703-4867-681
}

Received: 22 November 2019; Accepted: 8 January 2020; Published: 9 January 2020

\begin{abstract}
Tuber peeling is an essential unit operation prior to further processing. In this research, a batch loading tuber-peeling machine, with a capacity of $10 \mathrm{~kg} / \mathrm{min}$, was designed, fabricated and tested for cocoyam, sweet potato, yam and cassava tubers. The machine was designed to operate at a speed range of 350-750 rpm and time range of 5-12 min based on the principle of surface scratching. The performance of the machine was determined with respect to the peeling efficiency, percent weight of peel and flesh loss. The results showed that the peeling efficiency increased with an increase in the shaft speed for all the tubers. Also, the flesh loss and percent weight of peel decreased with an increase in the shaft speed for cassava and cocoyam tubers but increased for sweet potato and yam tubers $(p<0.05)$. Effective peeling of the tubers was achieved for sweet potato and yam at all the shaft speeds and time ranges considered.
\end{abstract}

Keywords: design; fabrication; evaluation; cassava; cocoyam; yam; peeling machine

\section{Introduction}

Root and tuber crops, including cassava (Manihot esculenta, Crantz), yam (Dioscorea spp.), sweet potato (Ipomoea batatas, Linneus) and cocoyam (Colocasia spp. and Xanthosoma sagittifolium), are widely grown and consumed as staple foods in many parts of Africa. According to the report of the International Institute of Tropical Agriculture [1], the production of the cassava, sweet potato, yam and cocoyam account for about $95 \%$ of the total root and tuber crops production in Africa. They are part of the most important energy sources in the human diet as they are highly enriched in carbohydrate. They can be consumed as vegetables or used as raw material for the small-scale industries at a global level, particularly in less-developed tropical countries. In some other places, they serve as cash crops that thrive where most other crops fail. These crops are also capable of providing efficient calorific energy almost double that of wheat and rice [2]. They also provide some minerals and essential vitamins, although a proportion of these elements may be lost during processing as, for example, in the case of cassava [3].

The quantity and quality of the protein in root and tuber crops are variable and relatively low. The advantages of root and tuber crops as staple foods includes the following: they are well adapted to diverse soil and environmental conditions and a wide variety of farming systems; they are highly efficient edible source of carbohydrates when compared to other food crops. The important limitations are their bulkiness with some the tubers weighing over $5 \mathrm{~kg}$ and perishability with a moisture content as high as $90 \%$. These are associated with high transport costs, a short shelf life and limited market margins, which impose serious constraints in the urban markets of most developing countries [1]. Production patterns reflect the agro-climate of the area, traditional farming practices and often the local cultural heritage. With few exceptions, roots and tubers are produced by small-scale farmers using traditional tools 
and without any inputs of fertilizers or chemicals for weed and pest control. Traditionally women have provided most of the labour for production, harvesting and processing. The perishability and post-harvest losses of root and tuber crops are the major constraints in their utilization [2].

\section{Related Work on Tuber-Peeling Operation}

Tuber crops are utilized extensively for human and livestock consumption as well as for industrial purposes. In order to expand the utilization of the tubers, there is need for an extensive exploration of their value addition by improving the shelf life of the products and enhancing foreign exchange. However, the processing of the tubers, especially the peeling operation, is usually labour intensive and requires a high level of mechanization in order to meet the high demand for the products. The peeling operation has become a major bottleneck in tuber processing, especially for cassava and yam, because of the difference in their physical properties. Many research efforts have, nevertheless, been reported for mechanical peeling operations of the root and tuber crops. For example, Table 1 shows some of the related works and their limitations.

Table 1. Related works, contributions and limitations.

\begin{tabular}{cccc}
\hline $\mathbf{s} / \mathbf{n}$ & Source & Contribution & Limitation \\
\hline 1 & Odigboh [4] & $\begin{array}{c}\text { Designed a three-model } \\
\text { cassava-peeling machine. }\end{array}$ & $\begin{array}{c}\text { Poor equipment calibration and high } \\
\text { tuber flesh loss. }\end{array}$ \\
\hline 2 & Singh and Shukla [5] & $\begin{array}{c}\text { Designed a power operated batch type } \\
\text { mechanical peeler for potatoes }\end{array}$ & $\begin{array}{c}\text { Poor equipment calibration and high } \\
\text { tuber flesh loss. }\end{array}$ \\
\hline 3 & Suter [6] & $\begin{array}{c}\text { Designed a roller-type potato peeler which } \\
\text { uses set of abrasive rollers. The motion of } \\
\text { roller is controlled by means of a sensor. }\end{array}$ & $\begin{array}{c}\text { Peeling efficiency was significantly low } \\
\text { with a high peeling loss. }\end{array}$ \\
\hline 5 & Akintunde et al. [7] & Designed a cassava-peeling machine & $\begin{array}{c}\text { Tuber are soaked in water } \\
\text { before peeling. }\end{array}$ \\
\hline 6 & Adetan et al. [8] & $\begin{array}{c}\text { Designed a spring-loaded cassava-peeling } \\
\text { machine with five spring-loading points } \\
\text { equally spaced at 140 mm }\end{array}$ & $\begin{array}{c}\text { Poor equipment calibration and high } \\
\text { tuber flesh loss. }\end{array}$ \\
\hline & Agbetoye et al. [9] & $\begin{array}{c}\text { Peveling efficiency was significantly low } \\
\text { with a high peeling loss. }\end{array}$ \\
\hline
\end{tabular}

The common problems associated with the popular designs, however, are the difficulty of equipment calibration, higher tuber flesh loss and lower machine efficiency. Also, most of the designs of the peeling machines are crop specific [10-12]. However, the design of a general-purpose peeling machine has not been reported hitherto. This new machine is aimed at addressing the problem of equipment calibration and tuber flesh loss. There is, therefore, a need to design a machine which can peel different kind of tuber crops irrespective of their sizes and shapes. The objectives of this research are to determine some physical and mechanical properties of cassava, sweet potatoes, yam and cocoyam essential in the design of a peeling machine for the tubers; to design and fabricate a multi-tuber peeling machine that would operate on a batch-loading system with a capacity of $100 \mathrm{~kg}$ per min; and to determine the performance with respect to the efficiency of the machine.

\section{Materials and Methods}

\subsection{Materials}

The materials for construction of the machine were selected based on availability, properties, machinability, affordability and economic considerations. Also, the strength of the materials for construction, toughness and stiffness were also taken into consideration. The materials used in the fabrication of the machine are listed in Table 2. 
Table 2. Materials for fabrication of the tuber peeling machine.

\begin{tabular}{ccc}
\hline $\mathbf{s} / \mathbf{n}$ & Materials & Dimension \\
\hline 1 & Iron pillow bearing & $25 \mathrm{~mm}$ \\
2 & Iron shaft & $30 \mathrm{~mm}$ \\
3 & Two pulleys & $500 \mathrm{~mm}$ and $70 \mathrm{~mm}$ \\
4 & Bolts ad nuts & 13 and $19 \mathrm{~mm}$ \\
5 & Angle iron bar & 3 inches \\
6 & Mild steel plate & $4 \mathrm{~mm}$ thick \\
7 & Iron flat bar & $30 \mathrm{~mm}$ and $5 \mathrm{~mm}$ \\
8 & Iron rod & $20 \mathrm{~mm}$ \\
9 & Hinges and lock & Standard size \\
10 & Other consumables (electrodes, grinding disc, cutting disc) & Standard sizes \\
\hline
\end{tabular}

\subsection{Determination of Properties of the Tuber Relevant to Machine Design}

Physical properties of the tubers, including size and shape are essential in determining the volume of the peeling drum [12]. The mechanical properties such as compression, shear stress and hardness are essential in the design of various machine components and for selecting the type of material for construction of the peeling sprockets. Most agricultural products are viscoelastic, they behave differently under static, tensile, or compressive forces, and under dynamic loading orientation. With the knowledge of the mechanical behavior of the tubers, it is possible to decide whether, for example, shearing or impact is best for the peeling operation [13]. Therefore, in this investigation, the mass of the tubers was determined, in 10 replicates each, using the Camry electronic weighing scale; which has high sensitivity with a precision of $0.01 \mathrm{~g}$. The size and shape were determined through the measurement of the tuber diameter, length, thickness or minor diameter in 10 replicates using a measuring tape and veneir caliper. The surface area of each of the tuber was determined from the data obtained from the tuber dimensions. The volume of each tuber with 10 replicates each was determined using the water-displacement method. The density was estimated for each tuber, from the information on masses and volume using the method reported by Fadeyibi and Osunde [13]. The compressive strength, shear stress and hardness of the tuber were also determined using a UTM (universal tensile testing machine).

\subsection{Machine General Description and Operating Principle}

The general purpose peeling machine was made up of a revolving cylindrical peeling drum lined with galvanized wire gauze, supported at both ends with two $25 \mathrm{~mm}$ pillow bearings mounted on a trapezoidal type of frame to support the machine by giving maximum stability as shown in Figure 1. A shaft supports the pulley and a v-belt was made to pass through the pillow bearing. A low-speed electric motor with a pulley rotation of 1:6 was used to provide the driving power and transfer the power to the peeling unit via the belt and pulley system. The peeling unit consists of a drum made of sharp edge wire gauze which rotates to give a smooth scratching and scraping of the tuber skin. The drum which rotates horizontally was tapered at both ends to a semi cone-like shape with galvanized steel plate. A V-belt with adequate tension was used to provide durability and required tension. The belt is meant to transmit power from the driving motor to the peeling drum via two pulleys. The pulley was attached to the shaft passing through the peeling drum and supported at both ends with pillow bearings. The pulley was rigid, hard and machinable, made from cast iron for the purpose of rigidity since it would be subjected to tension from the belt as well as torque and speed variations from the motor. A shaft was used based on design consideration, to match with the load to be subjected to thereby prevent bending and twisting. The bearing provided a frictionless circular motion for the shaft. The frame was made of 3 inches mild steel angle iron and was constructed into a trapezoidal shape to provide stability against the compressive force from the other parts of the machine; and help prevent vibration from the peeling drum and driver. 


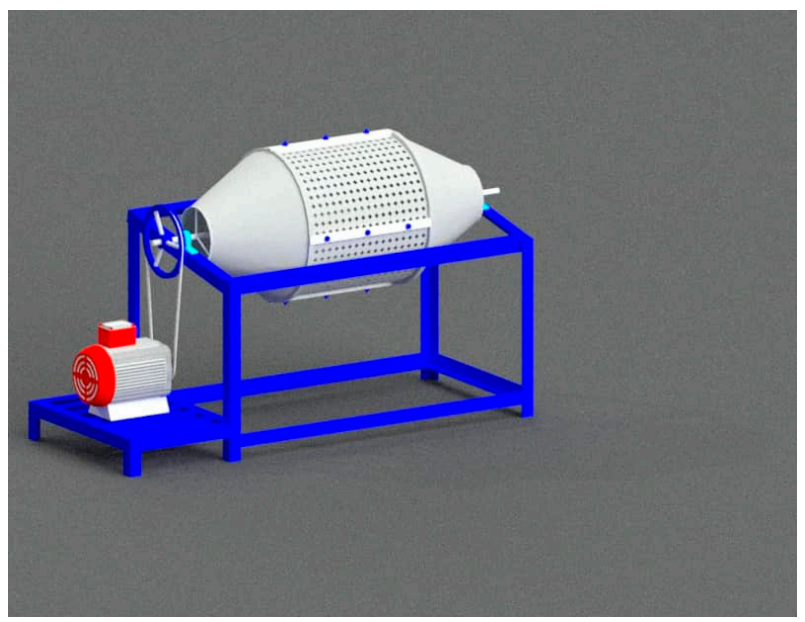

Figure 1. Model of the general purpose tuber-peeling machine.

\subsection{Design Analysis}

The general-purpose tuber peeling machine was designed bearing in mind the differences in the physical and the mechanical properties of the tubers under study. The machine was also designed such that it has a theoretical capacity of $10 \mathrm{~kg} / \mathrm{min}$ and is can peel all tubers to a minimum efficiency of $65 \%$. The materials of construction are readily available, and the capacity is higher than the manual peeling method. The labour input in a traditional method of peeling is considerably reduced and the complexity of mono-tuber peeler is also eradicated.

\subsubsection{Determination of Volume of Peeling Drum}

Since we know that the machine is designed to handle a $10 \mathrm{~kg}$ batch of tubers per min, theoretically, the mass of the tuber was taken as $10 \mathrm{~kg}$. Also, preliminary studies showed that the average density of all the four tubers was $7850 \mathrm{~kg} / \mathrm{m}^{3}$. Thus, the volume occupied by the tuber was computed using Equation (1).

$$
\rho=\frac{m}{v}
$$

where,

$m=$ mass of the tuber $(10 \mathrm{~kg})$

$\rho=$ density of the tubers $\left(7850 \mathrm{~kg} / \mathrm{m}^{3}\right)$

$v=$ volume of the tubers $\left(\mathrm{m}^{3}\right)$

The volume of the peeling drum was determined using Equation (2) [12].

$$
V=\pi \frac{D^{2} L}{4}
$$

where,

$L=$ length of the drum (mm)

$D=$ diameter of the drum $(\mathrm{mm})$

$V=$ volume of the peeling drum $\left(\mathrm{mm}^{3}\right)$

We know that the average length of all the tubers was $520 \mathrm{~mm}$ from the study of the physical properties of the tubers. Hence, a drum length of $600 \mathrm{~mm}$ was used in the design. Also, from the study of the physical properties, we know that the average mass of all the tubers is $1200 \mathrm{~g}=1.2 \mathrm{~kg}$. Thus, the number of tubers accommodated in $10 \mathrm{~kg}$ was computed from Equation (3) [12].

$$
n=\frac{m}{1.2}
$$


where

$n=$ number of tubers

Therefore, the diameter and the length of the drum used were $433.32 \mathrm{~mm}$ and $600 \mathrm{~mm}$, respectively.

\subsubsection{Determination of Tension in Belt}

Consider the belt pulley system arrangement shown in Figure 2. The tensions in the belt were determined using Equation (3) [14].

$$
2.3 \log \left(\frac{T_{1}}{T_{2}}\right)=\mu \theta
$$

where,

$\theta=$ angle of wrap of an open belt

$\mu=$ co-efficient of friction $=0.3$

$T_{1}=$ tension in the tight side of the belt $(\mathrm{N})$

$T_{2}=$ tension in the slack side of the belt $(\mathrm{N})$

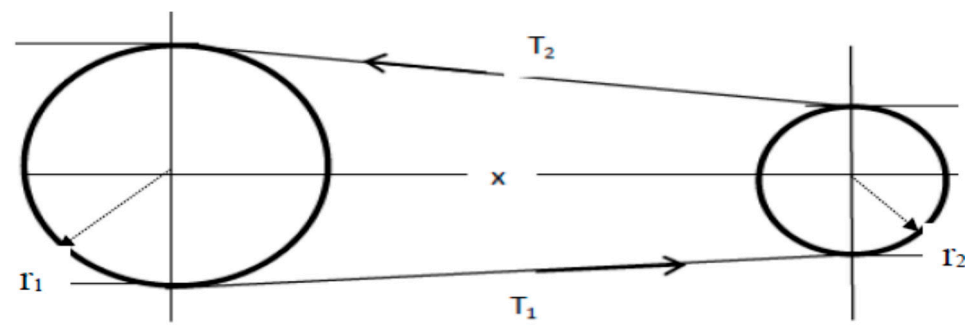

Figure 2. Design of length of belt.

The angle of lap was computed using Equations (5) and (6):

$$
\begin{gathered}
\sin \propto=\frac{r_{1}-r_{2}}{x} \\
\theta=180 \pm 2 \sin ^{-1}\left(\frac{r_{1}-r_{2}}{x}\right)
\end{gathered}
$$

where,

$r_{1}=$ radius of the machine pulley $(\mathrm{mm})$

$r_{2}=$ radius of the motor pulley $(\mathrm{mm})$

$\propto=$ angle of contact from belt (rad)

$x=$ distance between the two pulleys ( $\mathrm{mm})$.

The belt speed and power transmitted were computed using Equations (7) and (8).

$$
\begin{gathered}
V=\frac{\pi D N}{60} \\
P=\left(T_{1}-T_{2}\right) v
\end{gathered}
$$

where,

$D=$ diameter of driven pulley $(80 \mathrm{~mm})$

$N=$ speed of the motor $(1460 \mathrm{rpm})$

$P=$ power transmitted $(\mathrm{W})$;

$v=$ speed of the belt $(\mathrm{m} / \mathrm{s})$

$T_{1}$ and $T_{2}$ retained their usual meaning 


\subsubsection{Length of the Belt}

For this design, the center distance $C$ between the shaft pulley and motor pulley is given by the expression in Equation (9).

$$
C=\left(\frac{D+d}{2}\right)+d
$$

where,

$D$ is the shaft pulley diameter $(\mathrm{mm})$

$C_{d}$ is center distance $(\mathrm{mm})$

$d$ is diameter of driver pulley $(\mathrm{mm})$

We know that a $3 \mathrm{HP}$ motor has a speed of $1450 \mathrm{rpm}$ and pulley diameter of $80 \mathrm{~mm}$, thus we used this to evaluate the speed ratio using Equation (10):

$$
N_{1} D_{1}=N_{2} D_{2}
$$

where,

$N_{1}=$ speed of driven pulley

$N_{2}=$ speed of the electric motor $(1460 \mathrm{rpm})$

$D_{1}=$ diameter of the driven pulley

$D_{2}=$ diameter of the electric motor pulley $(80 \mathrm{~mm})$

\subsubsection{Power Requirement for Peeling Tubers}

Power to peel the tubers is the power required to drive the peeling drum and this was computed using Equation (11).

$$
P=T \frac{2 \pi S}{60}
$$

where,

$P=$ power to turn the peeling drum (W)

$S=$ speed of rotation of the drum (rpm). This was assumed to be $350 \mathrm{rpm}, 530 \mathrm{rpm}$ and $750 \mathrm{rpm}$.

$T=$ torque on the peeling drum $(\mathrm{Nm})$

However, we know that the torque on the peeling drum is a function of the mass of the drum, which includes the tubers contained in it, radius of gyration and acceleration of free fall according to the expression in Equation (12).

$$
T=m_{d} \times a \times r
$$

where,

$m=$ mass of the drum including tubers in it $(\mathrm{kg})$

$a=$ acceleration of free fall $\left(9.81 \mathrm{~m} / \mathrm{s}^{2}\right)$

$r=$ radius of the peeling drum $(0.217 \mathrm{~mm})$

$T=$ torque $(\mathrm{Nm})$

Using the speed of the peeling drum of $530 \mathrm{rpm}$, as suggested by Kurmi and Gupter [14] for tubers, the velocity of the rotating drum was computed from Equation (13).

$$
P=T \times s
$$

where, 
$P=$ power requirement for motor selection $(\mathrm{W})$

$T=$ torque generated $(\mathrm{Nm})$

$r=$ speed of the peeling drum (530 rpm)

\subsubsection{Shaft Diameter}

The size of the shaft diameter was computed using Equation (14) [14].

$$
D_{f}^{3}=\frac{16}{\pi S_{u}}\left(\sqrt{\left(K_{t} M_{t}\right)^{2}+\left(K_{b} M_{b}\right)^{2}}\right.
$$

where,

$D_{f}=$ shaft diameter $(\mathrm{m})$

$M_{b}=$ bending moment $(\mathrm{Nm})$

$M_{t}=$ torsional moment $(\mathrm{Nm})$

$K_{b}=$ combined shock and fatigue factor for bending moment (1.5)

$K_{t}=$ combined shock and fatigue factor for torsional moment (1.0)

$S_{u}=$ allowable sheer stress for shaft with keyway of $40 \mathrm{MN} / \mathrm{m}^{2}$ [15]

\subsection{Component Parts of the Machine}

The component parts of the machine are generally described in Figure 3. The machine is composed of a rotating drum built with wire gauze wounded on a frame made of iron rods and flat bars in a longitudinal manner. A shaft is made to pass through the centre of the drum supported at both ends with pillow bearings and at one end is mounted the pulley that enables the belt to be connected to the electric motor supported at the base with another frame. The entire component is placed on a frame support big enough to give the required rigidity. The drum has only one opening where the tubers are fed and discharged while the peels or wastes are passed through the perforated portion. 


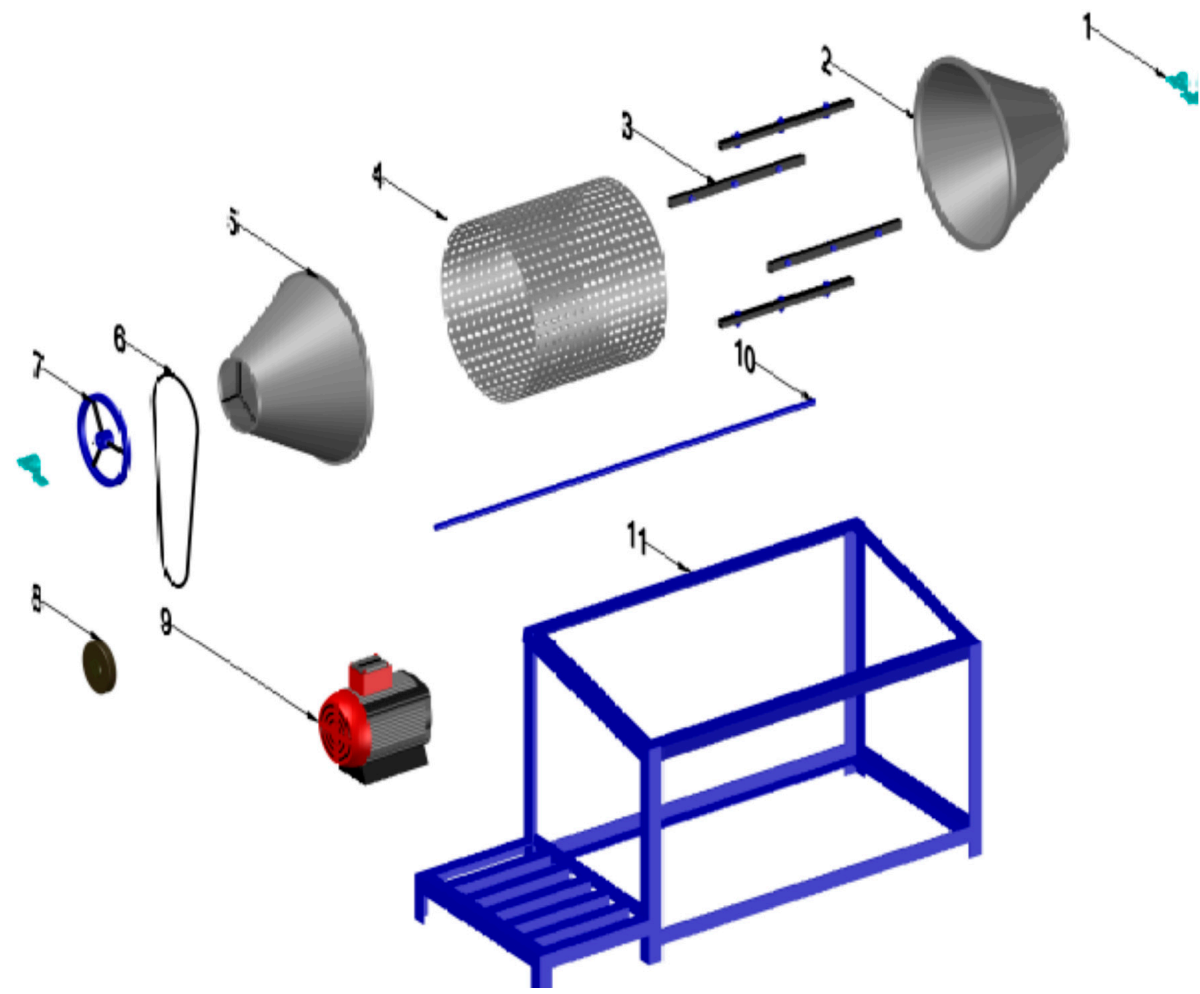

Figure 3. General machine description (1-handle; 2-right drum head; 3-rod; 4-wire gauze; 5-left drum head; 6-v-belt; 7- pulley; 8-motor seal; 9-electric motor; 10-shaft, 11- frame).

\subsection{Machine Technical Parameters}

Based on the design analysis of the tuber peeling machine, the values obtained are summarized as the technical parameters in Table 3.

Table 3. Machine technical parameters.

\begin{tabular}{|c|c|c|c|c|}
\hline sn & components & Dimension & Value & SI Unit \\
\hline \multirow{5}{*}{1} & \multirow{5}{*}{ Machine frame } & Upper length & 1130 & $\mathrm{~mm}$ \\
\hline & & Upper width & 700 & $\mathrm{~mm}$ \\
\hline & & Height & 700 & $\mathrm{~mm}$ \\
\hline & & Lower length & 1130 & $\mathrm{~mm}$ \\
\hline & & Lower width & 860 & $\mathrm{~mm}$ \\
\hline \multirow{3}{*}{2} & \multirow{3}{*}{ Shaft } & Length & 1200 & $\mathrm{~mm}$ \\
\hline & & Diameter & 30 & $\mathrm{~mm}$ \\
\hline & & Weight & 8.202 & $\mathrm{~kg}$ \\
\hline \multirow{2}{*}{3} & \multirow{2}{*}{ Bearing } & Diameter & 30 & $\mathrm{~mm}$ \\
\hline & & Weight & 1.04 & $\mathrm{~kg}$ \\
\hline \multirow{3}{*}{4} & \multirow{3}{*}{ Peeling drum } & Length & 600 & $\mathrm{~mm}$ \\
\hline & & Diameter & 400 & $\mathrm{~mm}$ \\
\hline & & Weight & 20 & $\mathrm{~kg}$ \\
\hline \multirow{3}{*}{5} & \multirow{3}{*}{ Pulley } & Diameter & 220 & $\mathrm{~mm}$ \\
\hline & & Weight & 1.348 & $\mathrm{~kg}$ \\
\hline & & Speed & 1460 & rpm \\
\hline \multirow{2}{*}{6} & \multirow{2}{*}{ Motor } & Power & 3.0 & $\mathrm{HP}$ \\
\hline & & Motor pulley diameter & 80 & $\mathrm{~mm}$ \\
\hline \multirow{2}{*}{7} & \multirow{2}{*}{ Belt } & Length & 717 & $\mathrm{~mm}$ \\
\hline & & Centre distance & 230 & $\mathrm{~mm}$ \\
\hline 8 & Capacity & Mass/time & 10 & $\mathrm{~kg} / \mathrm{min}$ \\
\hline
\end{tabular}




\subsection{Bill of Materials and Measurement}

The bill for engineering measurement and evaluation is shown in Table 4. Also, the bill for materials showing the make and model of each part of the system is shown in Table 5.

Table 4. Bill for engineering measurement and evaluation.

\begin{tabular}{|c|c|c|c|c|c|}
\hline Part & Material Make & Specification & Quantity & Unit cost (\$) & Total cost $(\$)$ \\
\hline 1 & Pillow bearing & $80 \mathrm{~mm}$ & 2 & 5.48 & 10.96 \\
\hline 2 & Shaft rod & 30 mm/1500 mm & 1 & 13.7 & 13.7 \\
\hline 3 & Wire gauze & Galvanized hard net & 1 length & 16.4 & 16.44 \\
\hline 4 & Galvanized steel plate & $2 \mathrm{~mm}$ thick half plate & $\frac{1}{2}$ plate & 23.3 & 11.64 \\
\hline 5 & Iron flat bar & $30 \mathrm{~mm}$ wide bar & $\frac{1}{2}$ length & 19.2 & 9.589 \\
\hline 6 & Iron flat bar & $\frac{1}{2}$ inch wide & 1 length & 6.85 & 6.849 \\
\hline 7 & Iron rod & $10 \mathrm{~mm}$ diameter & 1 length & 5.48 & 5.479 \\
\hline 8 & Iron rod & $20 \mathrm{~mm}$ diameter & $\frac{1}{2}$ length & 6.58 & 3.288 \\
\hline 9 & Hollow pipe ring & $30 \mathrm{~mm}$ diameter & 2 & 2.74 & 5.479 \\
\hline 10 & Angle iron & $\begin{array}{c}2 \times 2 \text { inches } \\
\text { Size } 13\end{array}$ & $\begin{array}{l}3 \text { length } \\
50 \text { set }\end{array}$ & 11 & 32.88 \\
\hline 11 & Bolt/nuts with washers & $\begin{array}{l}\text { Size } 17 \\
\text { Size } 19\end{array}$ & $\begin{array}{l}5 \text { set } \\
5 \text { set }\end{array}$ & 0.14 & 6.849 \\
\hline 12 & Binding wire & Thin wire & 1 length & 0.19 & 0.959 \\
\hline 13 & Lock and hangers & $\begin{array}{l}\text { Door lock average size } \\
30 \mathrm{~mm} \text { inner diameter }\end{array}$ & $\begin{array}{c}1 \text { set } \\
1\end{array}$ & 0.27 & 1.37 \\
\hline 14 & Pulley & $\begin{array}{c}220 \mathrm{~mm} \\
70 \mathrm{~mm} \\
300 \mathrm{~mm}\end{array}$ & $\begin{array}{l}1 \\
1\end{array}$ & 5.48 & 5.479 \\
\hline 15 & Electrode & Gauges 10 and 12 & 1 pct each & 1.37 & 1.37 \\
\hline 16 & Labour cost & & & 5.48 & 5.479 \\
\hline & Total & & & & 188.5 \\
\hline
\end{tabular}

Table 5. Bill for materials.

\begin{tabular}{cccc}
\hline Part No. & Material & Make & Model \\
1 & Handle & Galvanized iron rod, China & 80 mm \\
2 & Right-peeling drum head & Mild steel (MS), China & MS Mild steel 16 gauge \\
3 & Wire gauze & Galvanized hard net, China & 2 mm thick \\
4 & Left drum head & Mild steel, China & MS Mild steel 16 gauge \\
5 & v-belt & Vulcanized Rubber, US & Transmission, Type A \\
6 & Pulley & Mild steel rod, China & 16 guage \\
7 & Motor seal & US & 1450 rpm, single phase \\
8 & Electric motor & Horse Power Electric Motor, & China \\
9 & Shaft & Mild steel rod, China & 16 mm head or wrench size \\
11 & Bolt/nuts with washers & Mild steel, China & 16-guage angle iron bar \\
\hline
\end{tabular}

\subsection{Construction Detailed Drawing}

The isometric and orthographic projections of the peeling machine are shown in Figure 4. 

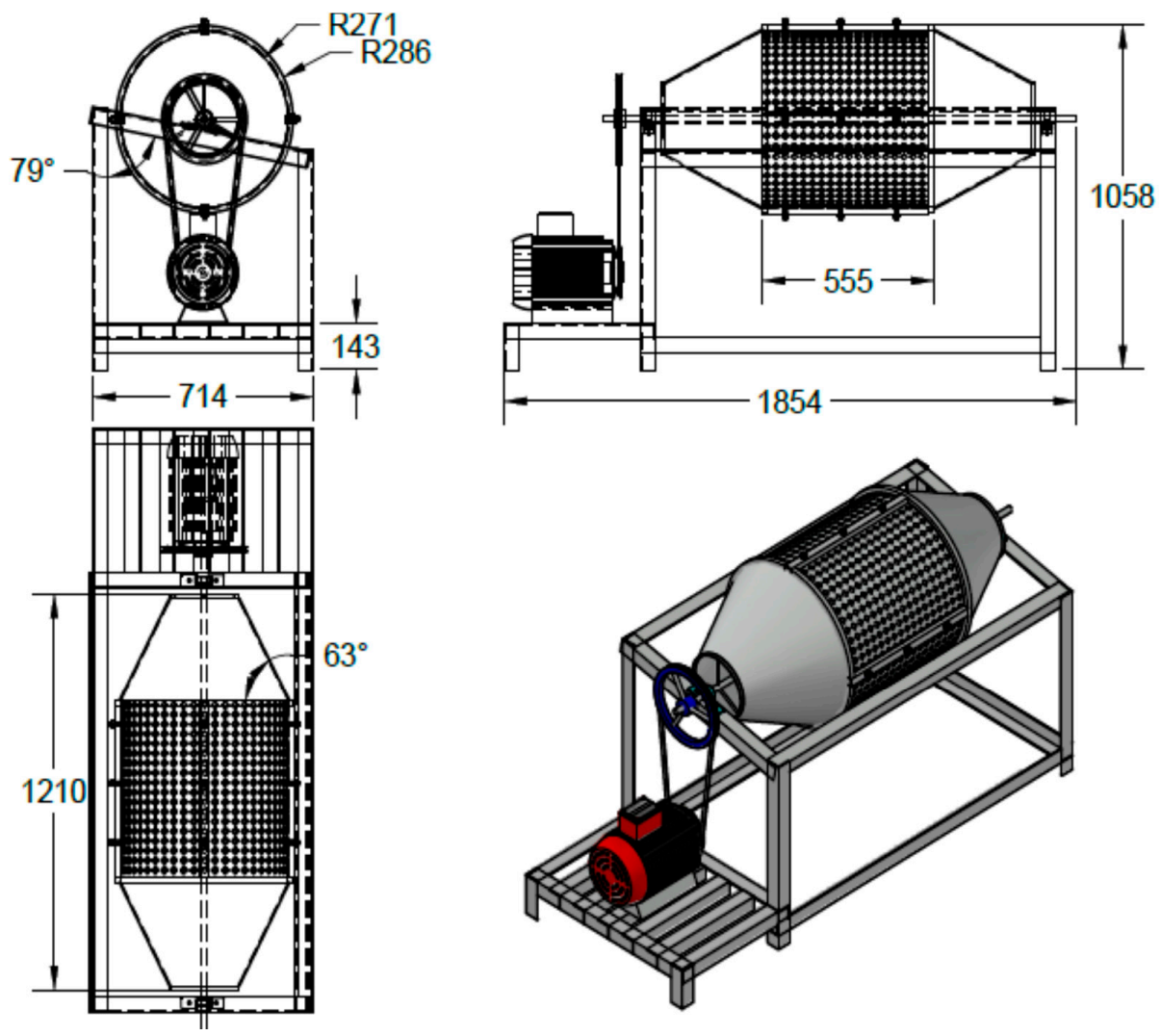

Figure 4. Isometric and orthographic projections of the tuber-peeling machine.

\subsection{Performance Evaluation}

\subsubsection{Sample Preparation}

We bought $10 \mathrm{~kg}$ of each tuber (cassava, potato, yam and cocoyam) from the main market in Omuaran, Kwara State, Nigeria. The tubers were cleaned to remove foreign matter, dust and dirt; and thereafter graded based on wholeness and freshness. Each of the tubers was fed gently through the inlet opening on the peeling drum, as shown in Figure 5. The machine was operated at three different speeds, namely $350 \mathrm{rpm}, 530 \mathrm{rpm}$ and $750 \mathrm{rpm}$ with respect to 334, 220 and $156 \mathrm{~mm}$ driving pulley arrangements. The peeling force was applied to the tubers by the scraping and scratching action of the rotating perforated wire gauze drum of the machine. The periderm or peeled flesh are discharged through the perforations and collected underneath the machine via a chaff collector bow, as shown in Figure 6. The machine performance was evaluated with respect to its throughput capacity, peeling efficiency and flesh loss efficiency. The procedure was replicated three times, and the average values recorded. 


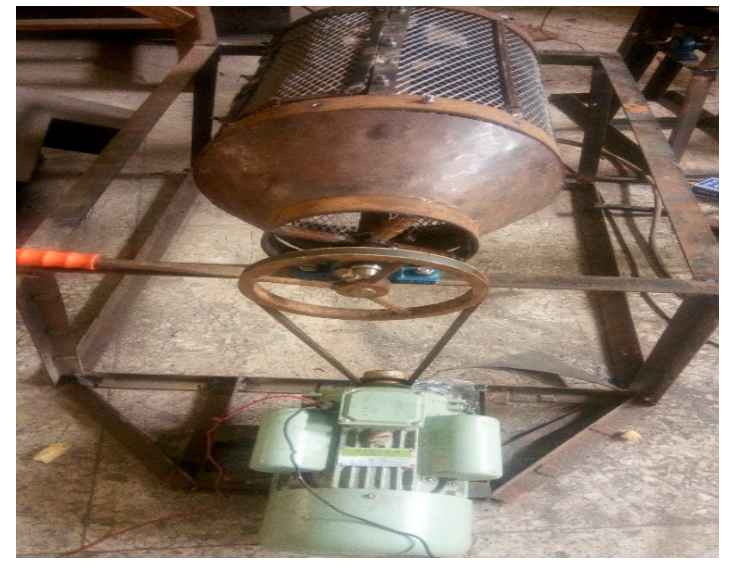

(a)

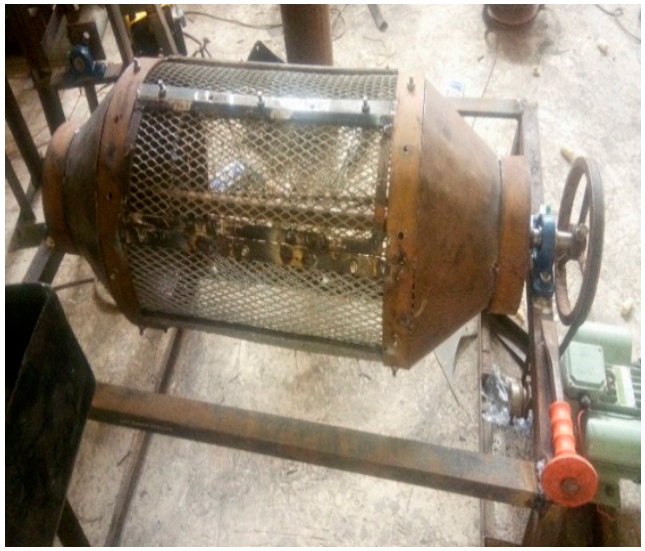

(b)

Figure 5. Tuber peeling machine (a) Side view; (b) Front view.

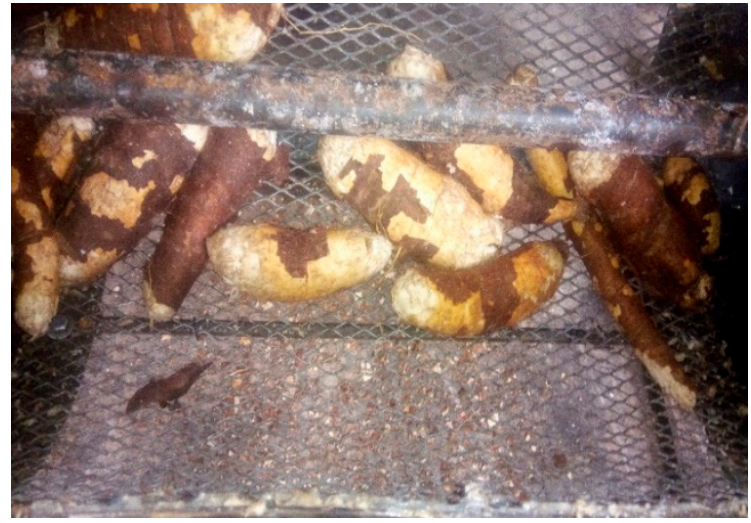

(a)

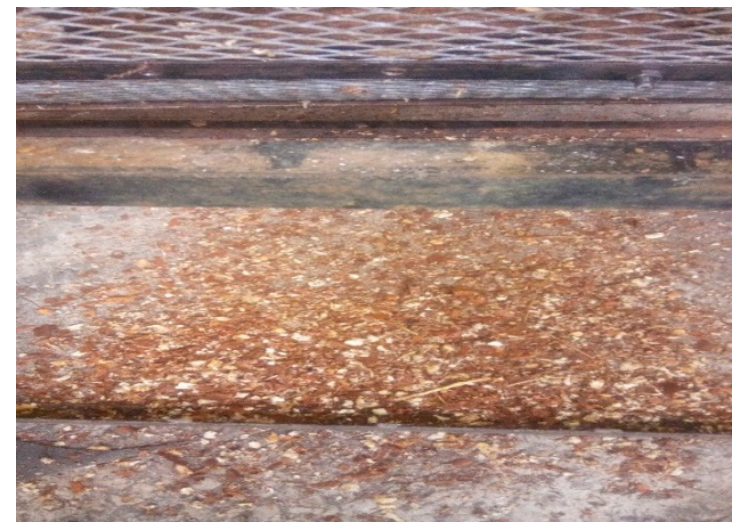

(b)

Figure 6. (a) Peeled cassava tubers; (b) cassava peels.

\subsubsection{Determination of Peeling Efficiency}

The peeling efficiency is the ratio of the throughput capacity to the theoretical capacity expressed as a percentage. This was determined, for each of the five tubers, using Equation (15), as given by Balami et al. [16] and Agrawal [17].

$$
\varepsilon=\frac{M_{p o}}{M_{p r}+M_{p o}} \times 100
$$

where,

$M_{p o}=$ weight of peel collected through the peel outlet of the machine $(\mathrm{kg})$

$M_{p r}=$ weight of tuber partially peeled in $\mathrm{kg}$

$\varepsilon=$ peeling efficiency

\subsubsection{Determination of Percentage Weight of Peel and Flesh Loss}

The percentage weight of peel and flesh loss were calculated using Equations (16) and (17), respectively [17].

$$
W_{p}=\frac{M_{p}}{M_{o}} \times 100 \%
$$




$$
\mathrm{FL}=\frac{M_{f}}{M_{o}} \times 100 \%
$$

where,

$\mathrm{FL}=$ flesh loss percentage $(\%)$

$W_{p}=$ percentage weight of peel $(\%)$

$M_{p}=$ weight of peel $(\mathrm{kg})$

$M_{f}=$ weight of flesh removed $(\mathrm{kg})$

$M_{o}=$ total weight of tuber $(\mathrm{kg})$

\section{Results and Discussion}

\subsection{Physical Properties of Some Selected Tuber Crops}

The results obtained for the physical properties of cassava, cocoyam, potatoes and yam are shown in Figures 7-9. The average tuber dimension and frontal area for cassava and yam tubers are more than those of sweet potato and cocoyam (Figures 7 and 8). The average tuber density is high for cassava followed by cocoyam and least for yam tuber as shown in Figure 9. The data obtained was used in the design of the tuber-peeling machine. For instance, the average tuber density was essentially used to determine the volume of the peeling drum in this investigation.

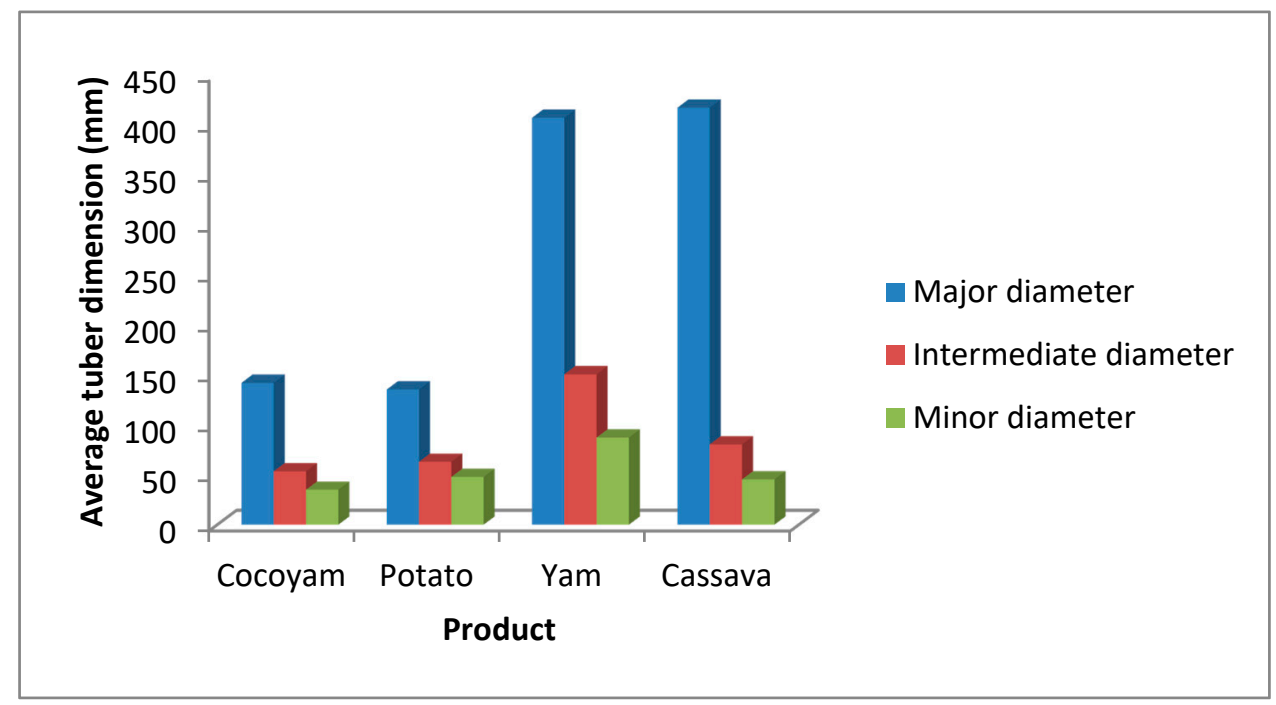

Figure 7. Comparison of tuber axial dimensions. 


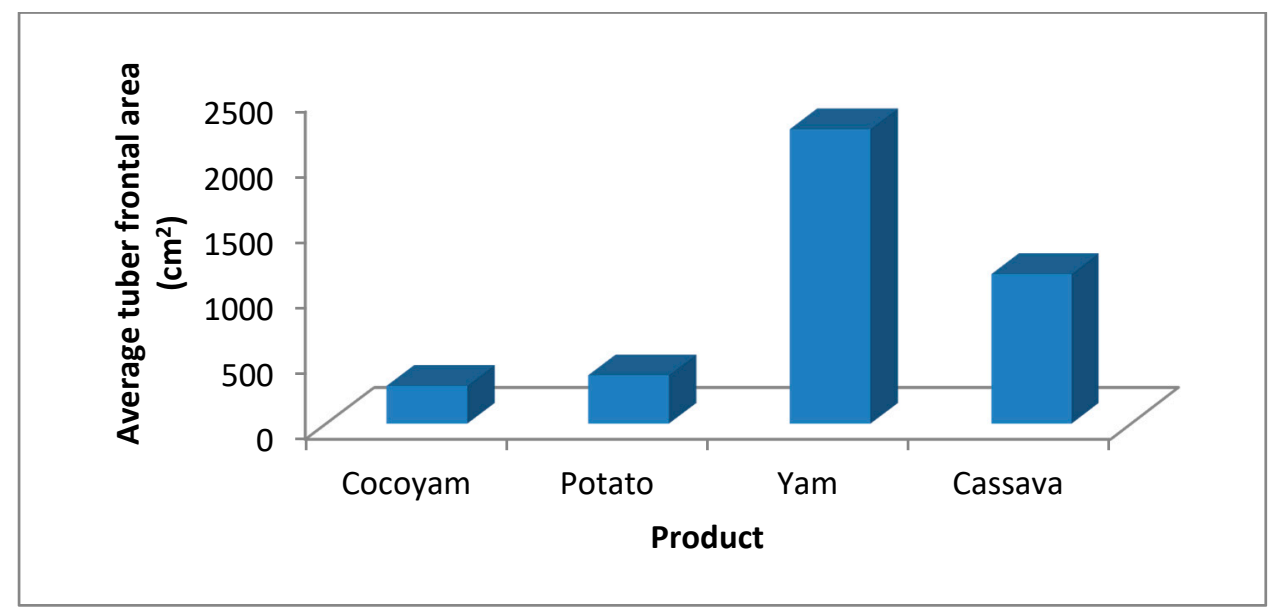

Figure 8. Comparison of tubers' frontal area.

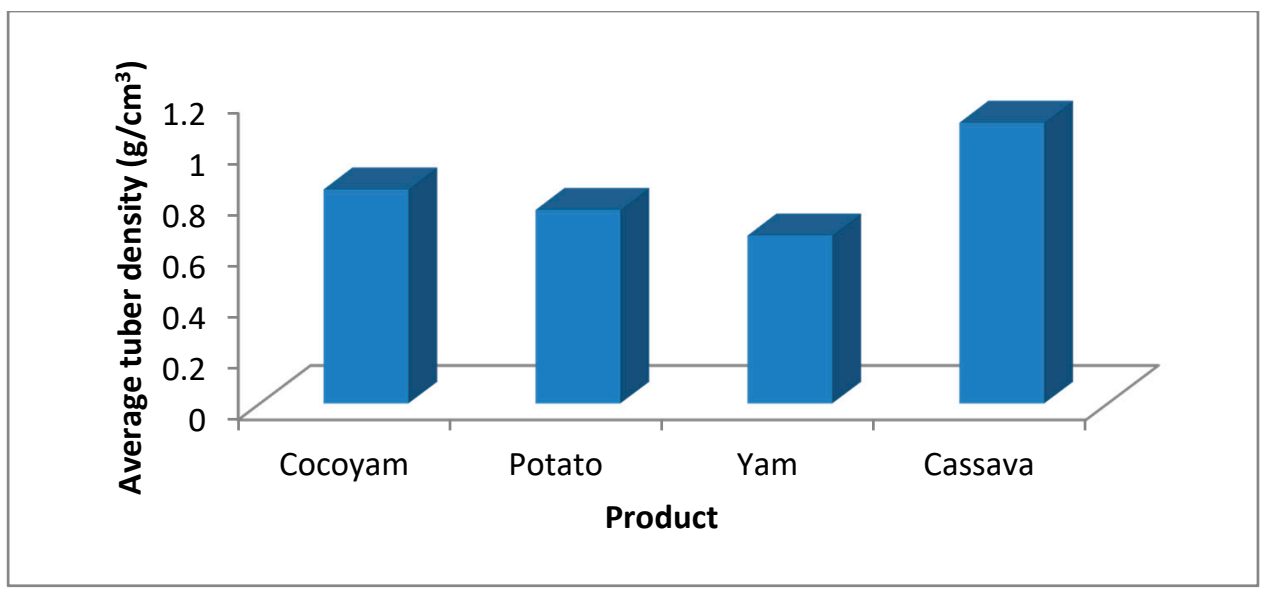

Figure 9. Comparison of tubers' density.

\subsection{Effect of Shaft Speed on the Throughput Capacity}

The effect of shaft speed on the throughput capacity of the machine is shown in Figure 10. The capacity of the machine increased with an increase in the speed of the machine for all the four tubers. Also, it was discovered that cocoyam has the highest throughput capacity followed by sweet potato. In a similar investigation, Olukunle and Jimoh [13] reported an increase of the throughput capacity of a cassava-peeling machine with an increase in the shaft speed. Also, Olukunle and Akinnuli [18] in their work on an automated cassava peeler reported that the throughput capacity increased with an increase in conveyor speed and decreased in the brush speed. This may mean that more tubers are peeled with an increase in the resident or peeling time.

\subsection{Effect of Shaft Speed on the Peeling Efficiency}

The effect of shaft speed on the peeling efficiency of the machine is shown in Table 6. The result revealed an increase in the efficiency of peeling for all the tubers with an increase in the shaft speed. It can be seen that the efficiency of the machine for cocoyam tuber peeling increased from $64.1 \%$ at speed of $350 \mathrm{rpm}$ to $74.6 \%$ at $750 \mathrm{rpm}$. The machine efficiency increased from $41.4 \%$ to $63.8 \%$ with an increase in the speed of 350 to $750 \mathrm{rpm}$ for cassava. Also, it appears that the machine is suitable for cocoyam peeling since it provided higher efficiency and lower flesh loss in comparison with the other tubers considered. The maximum peeling efficiency was obtained for cocoyam at a speed of $750 \mathrm{rpm}$, followed by sweet potato. The least efficiency was seen for yam and cassava at the speed of $350 \mathrm{rpm}$. The difference in the efficiency of the various tubers may not be unconnected with their size 
differences and moisture contents. The research efforts of Singh and Shukla [5], Olukunle and Jimoh [12], Olukunle and Akinnuli [18], Adetoro [19], Oluwole et al. [20], Jayashree and Visvanathan [21] and Balami et al. [22] who reported effects of shaft speed on peeling efficiency of various tubers corroborate the present investigation. Thus, the peeling efficiency was higher for cocoyam tubers than the other tubers considered.

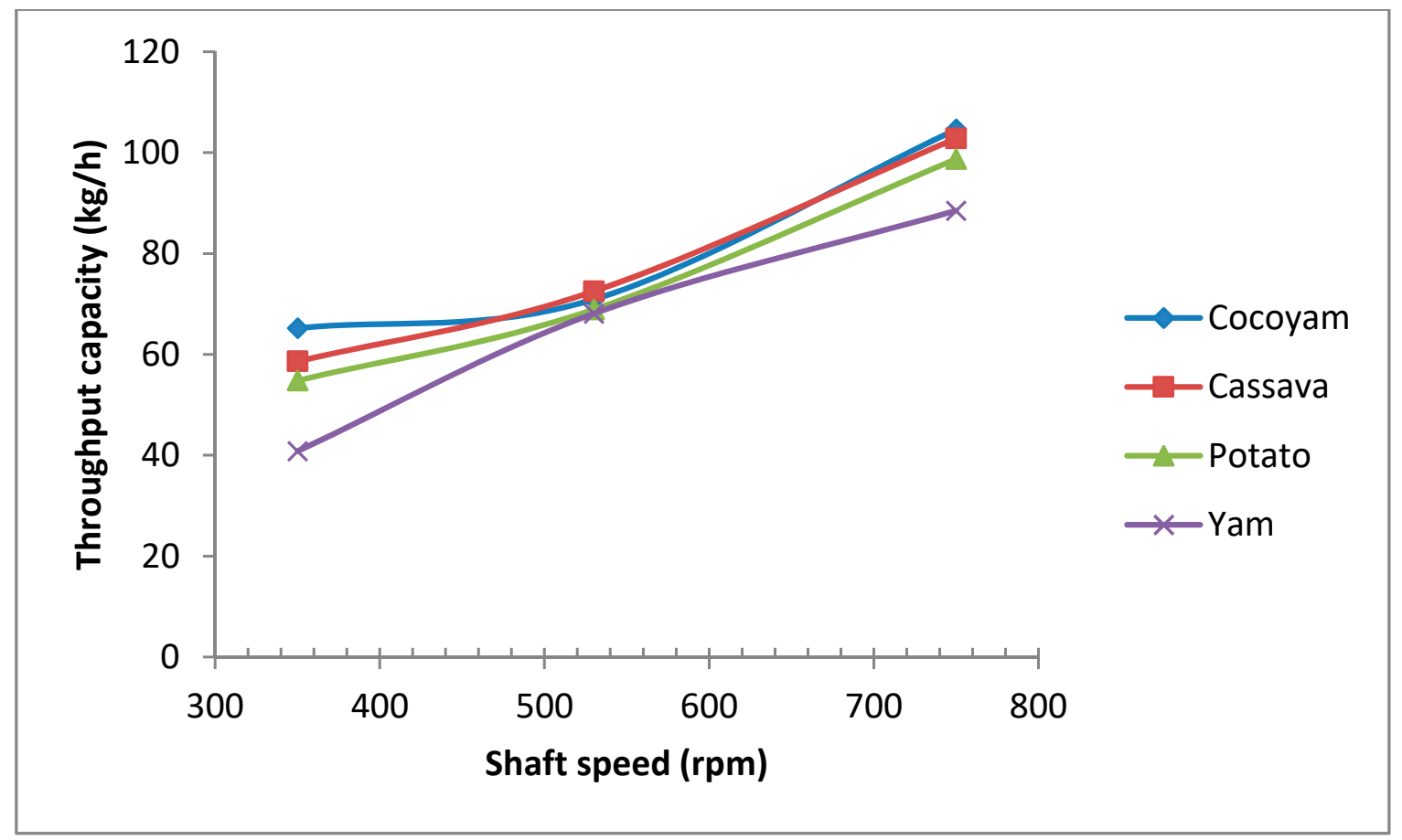

Figure 10. Effect of shaft speed on the throughput capacity.

Table 6. Effect of shaft speed on the peeling efficiency.

\begin{tabular}{cccc}
\hline Runs & Speed & Product & Peeling Efficiency (\%) \\
\hline 1 & 350 & Cocoyam & 64.1 \\
7 & 530 & Cocoyam & 70.6 \\
5 & 750 & Cocoyam & 74.6 \\
4 & 350 & Cassava & 41.4 \\
6 & 530 & Cassava & 57.4 \\
1 & 750 & Cassava & 63.8 \\
8 & 350 & Potato & 64.8 \\
2 & 530 & Potato & 69.5 \\
12 & 750 & Potato & 72.3 \\
9 & 350 & Yam & 40.2 \\
11 & 530 & Yam & 52.4 \\
10 & 750 & Yam & 61.1 \\
\hline
\end{tabular}

\subsection{Effect of Shaft Speed on the Flesh Loss and the Weight of Peel}

The amount of tuber waste produced was estimated as a function of the tuber flesh loss and the percent weight of peels. The effect of shaft speed on the tuber flesh loss and percentage weight of peel are shown in Figures 11 and 12, respectively. The flesh loss and percent weight of peels increased with an increase in the shaft speed. Obviously, there are more flesh losses with an increase in the speed for all other tubers except cassava (Figure 12). The reason for this may not be unconnected with the clear differences in the shapes and sizes of the tubers. It is possible to reduce the amount of tuber wastes generated by increasing the shaft speed. However, this will require proper sorting of the tubers 
based on size. Also, the percent weight of peels and tuber flesh loss were found to be slightly less than $20 \%$ and $22 \%$ of the total weight of the tubers peeled. These values are slightly less than those reported by Olukunle and Jimoh [12], Olukunle and Akinnuli [18], Adetoro [19] and Oluwole et al. [20]. Consequently, the machine can reliably be used for cassava, cocoyam, yam and sweet potato peeling.

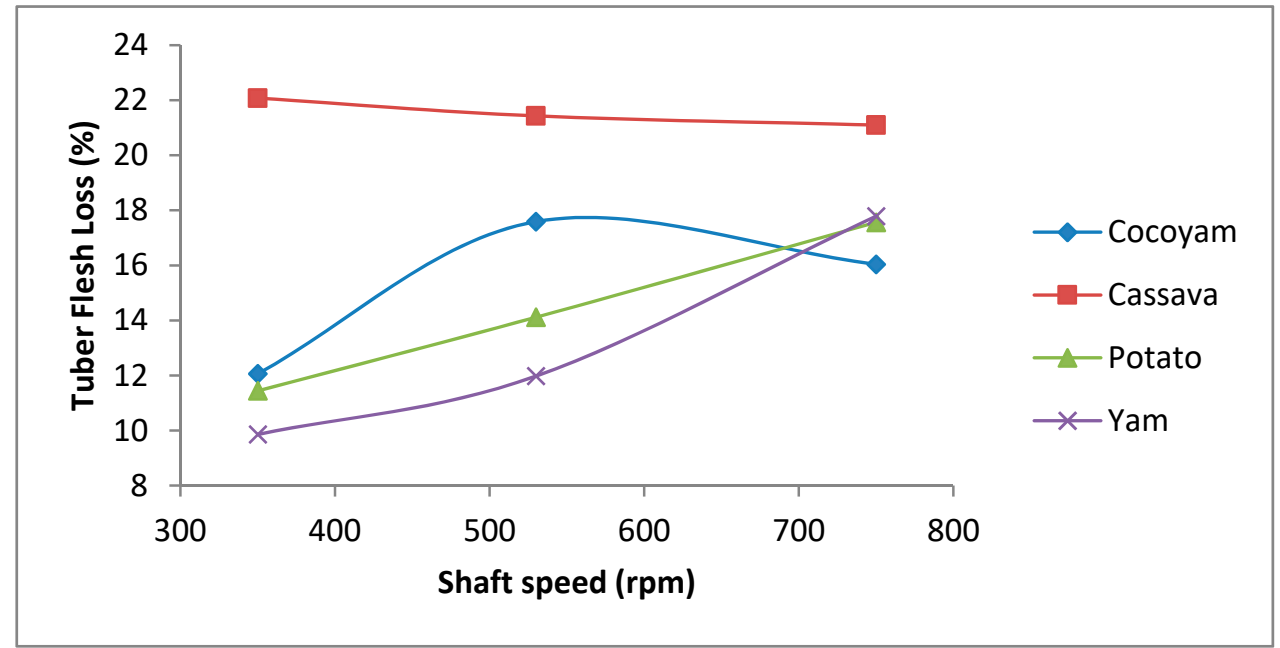

Figure 11. Effect of shaft speed on the flesh loss efficiency.

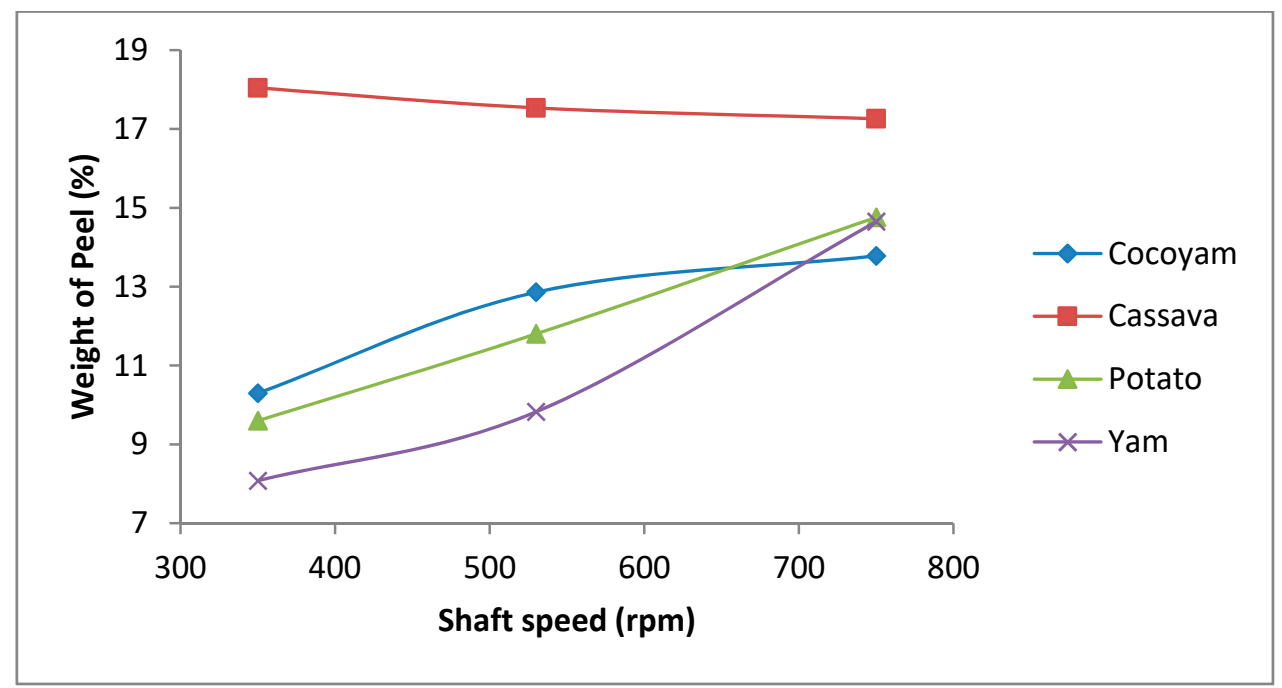

Figure 12. Effect of shaft speed on the percentage weight of peel.

\section{Conclusions}

A simple tuber peeling machine has been designed and fabricated for peeling different kind of tubers irrespective of size and shape of the products. The machine was designed to operate at the speed range of 350-750 rpm and time range of 5-12 min based on the principle of surface scratching. The performance of the machine was determined with respect to the peeling efficiency, weight of peel and tuber flesh loss. The results showed that the peeling efficiency increased with an increase in the shaft speed for all the tubers. Effective peeling was achieved for all the tubers since the amount of flesh loss and percent weight of peel were only $20 \%$ and $25 \%$ of the total weight of the tubers, respectively. The machine is easy to operate, and it can be afforded by commercial tuber processors and small-scale processors. 
Author Contributions: Conceptualization, A.F.; Data curation, O.F.A.; Formal analysis, O.F.A.; Funding acquisition, A.F.; Methodology, A.F.; Project administration, A.F.; Supervision, A.F.; Writing-original draft, O.F.A.; Writing - review and editing, A.F. All authors have read and agreed to the published version of the manuscript.

Funding: This research received no external funding.

Conflicts of Interest: The authors declare no conflict of interest.

\section{Abbreviations}

$\begin{array}{lll}\text { Symbol } & \text { Meaning } & \text { SI Unit } \\ m & \text { Mass of tuber } & \mathrm{kg} \\ P & \text { Density of tuber } & \mathrm{kg} / \mathrm{m}^{3} \\ V & \text { Volume of tuber } & \mathrm{m}^{3} \\ L & \text { Length of the peeling drum } & \mathrm{mm} \\ D_{d} & \text { Diameter of the peeling drum } & \mathrm{mm} \\ V & \text { Volume of the peeling drum } & \mathrm{mm}^{3} \\ n & \text { Number of tubers } & \mathrm{pieces} \\ \mu & \text { Coefficient of friction } & - \\ T_{1} & \text { Tension on tight side of the belt } & \mathrm{N} \\ T_{2} & \text { Tension on slag side of the belt } & \mathrm{N} \\ \alpha & \text { Angle of contact from belt } & \mathrm{rad} \\ x & \text { Distance between pulleys } & \mathrm{mm} \\ D & \text { Diameter of the driven pulley } & \mathrm{mm} \\ N & \text { Speed of electric motor } & \mathrm{rpm} \\ P & \text { Power transmitted } & \mathrm{W} \\ c_{d} & \text { Centre distance } & \mathrm{mm} \\ S & \text { Speed of rotation of the drum } & \mathrm{rpm} \\ T & \text { Torque on the peeling drum } & \mathrm{Nm} \\ m_{d} & \text { Mass of drum including tuber in it } & \mathrm{kg} \\ D_{f} & \text { Shaft diameter } & \mathrm{mm} \\ \varepsilon & \text { Peeling efficiency } & \% \\ M_{p o} & \text { Weight of peels collected via outlet } & \mathrm{kg} \\ M_{p r} & \text { Weight of tuber partially peeled } & \mathrm{kg} \\ W_{p} & \text { Percent weight of peels } & \% \\ \mathrm{FL} & \text { Tuber flesh loss } & \% \\ M_{p} & \text { Weight of peels } & \mathrm{kg} \\ & & \end{array}$

\section{References}

1. FAO. FAO Production Year Book; Food and Agricultural Organization of the United Nations: Rome, Italy, 1990.

2. FAO. FAO Production Year Book; Food and Agricultural Organization of the United Nations: Rome, Italy, 1993.

3. Abdulkadir, B.H. Design and Fabrication of a Cassava Peeling Machine. IOSR J. Eng. 2012, 2, 1-8.

4. Odigboh, E.U. Model III batch process cassava peeling machine. In Proceedings of the International Conference of Agricultural Engineering, Westin Hotel, Seattle, WA, USA, 19-22 September 1988.

5. Singh, K.K.; Shukla, B.D. Abrasive Peeling of Potatoes. J. Food Eng. 1995, 26, 431-442. [CrossRef]

6. Suter, M.L.; FMC Technologies Inc. Peeling Apparatus Having Feeder Control Based upon Load and Associated Methods. U.S. Patent 6,431,061, 13 August 2002.

7. Akintunde, B.O.; Oyawale, F.A.; Tunde-Akintunde, T.Y. Design and fabrication of a cassava peeling Machine. Niger. Food J. 2005, 23, 231-238. [CrossRef]

8. Adetan, D.A.; Adekoya, L.O.; Aluko, O.B.; Mankanjuola, G.A. An experimental mechanical cassava tubers peeling Machine. J. Agric. Eng. Technol. 2005, 13, 27-34.

9. Agbetoye, L.A.S. Development in Cassava Harvesting Mechanization. West Indian J. Eng. 1999, 22, 11-19.

10. Emadi, B.; Kosse, V.; Yarlagadda, P. Abrasive Peeling of Pumpkin. J. Food Eng. 2007, 89, 448-452. [CrossRef]

11. Olukunle, O.J.; Jimoh, M.O. Comparative Analysis and Performance Evaluation of three Cassava Peeling Machines. Int. Res. J. Eng. Sci. Technol. Innov. 2012, 1, 94-102. 
12. Jimoh, O.M.; Ademosun, C.O.; Olukunle, J.O. Effect of Physical and Mechanical Properties of Cassava Tubers on the Performance of an Automated Peeling Machine. Niger. J. Eng. Appl. Sci. 2012, 5, 47-60.

13. Fadeyibi, A.; Osunde, Z.D. Thermo-physical properties of Rubber Seed useful in the Design of Storage Structure. Int. J. Agric. Biol. Eng. 2012, 5, 62-66.

14. Khurmi, R.S.; Gupta, J.K. Textbook of Machine Design, 25th ed.; S. Chand \& Co. Ltd.: New Delhi, India, 2005.

15. Rajput, R.K. Elements of Mechanical Engineering; Lakshmi publishers: New Delhi, India, 2013.

16. Balami, A.A.; Mohammed, I.A.; Adebayo, S.E.; Adgidzi, D.; Adelemi, A.A. The Relevance of Some Engineering properties of Cocoyam (Colocasia Esculenta) in the Design of Post-harvest processing Machine. Acad. Res. Int. 2012, 2, 53-59.

17. Agrawal, Y.C. Ginger Peeling Machine Parameters. Agric. Mech. Asia Afr. Lat. Am. 1987, 18, $59-62$.

18. Olukunle, O.J.; Akinnuli, B.O. Theory of an Automated Cassava Peeling System. Int. J. Eng. Innov. Technol. 2013, 2, 177-184.

19. Adetoro, K.A. Development of a Yam Peeling machine. Glob. Adv. Res. J. Eng. Technol. Innov. 2012, 1, 85-88.

20. Oluwole, O.O.; Adio, M.A. Design and Construction of a Batch Cassava Peeling Machine. J. Mech. Eng. Automat. 2013, 3, 16-21.

21. Jayashree, E.; Visvanathan, R. Studies on Development of Concentric Drum, Brush type Ginger Peeling. Agric. Mech. Asia Afr. Lat. Am. 2014, 45, 82-87.

22. Balami, A.A.; Dauda, S.M.; Mohammed, I.S.; Agunsoye, J.K.; Abu, H.; Abubakar, I.; Hamad, D. Design and Fabrication of a Cocoyam (Colocasia Esculauta) Peeling Machine. Internet Food Res. J. 2014, 23, 565-570.

(C) 2020 by the authors. Licensee MDPI, Basel, Switzerland. This article is an open access article distributed under the terms and conditions of the Creative Commons Attribution (CC BY) license (http://creativecommons.org/licenses/by/4.0/). 